\title{
PENGUKURAN MINAT BACA MAHASISWA DENGAN METODE CLUSTERING DI PERPUSTAKAAN AKADEMI KEPERAWATAN RS.DUSTIRA CIMAHI MENGGUNAKAN DATA MINING
}

\author{
Eryan Ahmad Firdaus ${ }^{1}$, Shanti Maulani ${ }^{2}$, Asep Budi Dharmawan ${ }^{3}$ \\ 1,2,3 Akademi Keperwatan RS.Dustira Cimahi \\ Email: 1eryan.ahmad@gmail.com, ${ }^{2}$ shanti.maulani@gmail.com, \\ ${ }^{3}$ dharmawanbudi5758@gmail.com
}

\begin{abstract}
Abstrak
Berdasarkan hasil penelitian untuk mengukur minat baca mahasiswa di Perpustakaan Akper RS. Dustira Cimahi dapat dilakukan dengan mengunakan metode clustering. Dalam penelitian ini menggunakan data perpustakaan yaitu database Perpustakaan Akper RS. Dustira Cimahi yang diambil dari tiga sumber tabel utama seperti tabel visitorlog, tabel koleksi dan tabel anggota yang kemudian akan dilakukan pengintegrasian lalu diseleksi agar dapat disatukan menjadi sebuah data warehouse. Dalam menggunakan data mining dilakukan pengecekan dari mulai judul koleksi buku untuk mengetahui judul buku yang sangat diminati oleh mahasiswa dan mahasiswa tingkat berapa yang paling banyak meminjam buku dan juga paling banyak buku yang dibaca diperpustakaan Akper RS. Dustira Cimahi. Dari Informasi tersebut dapat disimpulkan bahwa mahasiswa tingkat akhir lebih suka meminjam dan membaca buku daripada mahasiswa yang masih semester awal. Buku dengan judul Pengantar Kebutuhan Dasar Manusia paling sangat diminati dan banyak dipinjam serta dibaca sedangkan judul koleksi buku yang sangat sedikit dipinjam dan dibaca yaitu buku dengan judul Belajar Ilmu Komputer. Dengan menggunakan metode cluster dapat diketahui bahwa kategori buku Keperawatan adalah buku yang sangat diminati oleh mahasiswa sedangkan buku Ilmu Komputer termasuk kategori koleksi buku yang sangat sedikit diminati oleh seluruh mahasiswa keperawatan.
\end{abstract}

Kata Kunci: Metode Clustering, Data Mining, Tabel Koleksi, Tabel Anggota, Tabel Visitorlog.

\footnotetext{
Abstract

Based on the results of research to measure students' reading interest in Akper RS. Dustira Cimahi Library can be done by using clustering method. In this study using library data, namely Akper RS. Dustira Cimahi library database taken from three main table sources such as visitorlog table, collection table and member table which will then be integrated and selected so that it can be put together into a data warehouse. In using data mining, checking the title of the book collection to find out the title of the book that is in great demand by students and students of what level borrows the most books and also the most books read in Akper RS. Dustira Cimahi library. From this information, it can be concluded that final-level students prefer to borrow and read books than students who are still in the early semester. The book with the title Introduction to Basic Human Needs is most in demand and widely borrowed and read while the title of the collection of books that are very little borrowed and read is a book with the title Learn Computer Science. By using the cluster method it can be known that the category of Nursing books is a book that is in great demand by students while Computer Science books belong to the category of book collections that are very little in demand by all nursing students.
} 
Keywords: Clustering Method, Data Mining, Collection Table, Member Table, Visitorlog Table.

\section{PENDAHULUAN}

Pada saat ini penggunaan teknologi sistem informasi telah menjadi kebutuhan manusia untuk mencari berbagai sumber yang dapat memberikan manfaat besar terhadap perubahan-perubahan yang menjadi dasar pada suatu struktur dan manajemen organisasi, baik pendidikan, kesehatan, penelitian, dan transportasi. Perubahan yang sangat cepat dalam penggunaan teknologi untuk penyimpanan dan pengumpulan data menjadi lebih mudah di suatu organisasi dalam menggabungkan sejumlah data yang berukuran besar.

Data mining merupakan proses untuk menggali (mining) pengetahuan dan informasi baru dari data yang berjumlah banyak pada data warehouse, dengan menggunakan kecerdasan buatan (Artificial Intelegence) [1], dilihat dari statistik dan kajian matematika. Data mining adalah teknologi yang mampu menghubungkan antara komunikasi pelaku dan juga data.

- Metode data mining digunakan untuk memproses data yang besaruntuk menemukan polaa baru dalam teknik analisa data yang tergambar dalam data mining dengan metode cluster. Clustering yaitu pengelompokan datadata berdasarkan parameter dan objek. Metode cluster memiliki kemiripan data antara yang satu dengan yang lain. Data dalam clustrering yang dikelompokan adalah data pengunjung dan data koleksi judul buku yang sangat banyak diminati oleh mahasiswa untuk dibaca dan dipinjam dari Perpustakaan Akper RS. Dustira Cimahi.

Perpustakaan Akper RS. Dustira Cimahi bertujuan untuk dapat mendukung serta membantu dalam memenuhi berbagai kebutuhan sistem informasi ilmiah dalam sivitas akademika. Perpustakaan Akper RS. Dustira sering dimanfaatkan oleh banyak mahasiswa untuk melakukan proses peminjaman dan proses membaca buku diperpustakaan tersebut. Adanya perpustakaan memberikan maafaat sangat besar untuk melakukan proses pengajaran baik itu dalam proses belajar ataupun proses untuk mengajar, sehingga akan mempermudah dalam proses pengajaran tersebut. Kemudian dibantu juga dengan berbagai fasilitas dalam mendukung kebutuhan perpustakaan tersebut, seperti buku teks, buku sumber bahan ajar, dan sebagainya, yang disiapkan oleh perpustakaan. Minat adalah kecenderungan hati, gairah dan keinginan yang tinggi terhadap sesuatu [2].

Maka dalam hal ini akan muncul minat baca yang ada pada diri mahasiswa dan didorong oleh lingkukan keluarga dalam memberikan motivasi minat baca. Minat baca sangat diperlukan dalam pengembangan didunia pendidikan. Sedikitnya dalam mngembangkan minat baca adanya faktor kesediaan koleksi buku atau tugas yang sedikit diberikan oleh dosen yang berhubungan dengan literasi. Untuk melihat minat baca yang tingi bisa dilihat dari jumlah pengunjung dan jumlah buku yang banyak dipinjam serta dibaca.

Perpustakaan membuat laporan untuk mengetahui jumlah pengunjung dengan cara melihat data peminjaman buku. Data peminjaman buku dapat menjadi bahan untuk melihat besarnya minat baca yang akan dijadikan laporan bulanan ataupun tahunan. Jadi apakah data peminjaman buku hanya dibuat untuk data laporan bulanan atau tahunan saja oleh pihak perpustakaan?. Bila ini terus terjadi maka setiap tahunnya data akan menjadi besar dan terus menumpuk. Bila hal ini terjadi akan 
JURNAL NUANSA INFORMATIKA

Volume 15 Nomor 1, Januari 2021

menjadi laporan perpustakaan dan tumpukan data yang disimpan oleh pihak perpustakaan.

\section{METODE PENELITIAN}

Untuk melakukan pengkajian penelitian ini peneliti menggunakan metode deskriptif karena yang diteliti permasalahnnya bersumber dari datadata yang memiliki sifat fakta seperti data angota perpustakaan yang diambil hanya, data peminjam buku dan data koleksi buku sangat diminati oleh mahasiswa yang mengunjungi perpustakaan Akper RS. Dustira Cimahi.

Dalam menganalisis data mining ini dilakukan beberapa proses tahapan Knowledge Discovery in Databases (KDD) yaitu terdiri dari Data Cleaning, Data Integration, Data Selection, Data Transformation, Proses Mining, Pattern Evaluation, dan Knowledge Presentation [3]. Beberapa tahapan data mining terdiri dari 7 tahapan yaitu:

1. Tahapan membersihkan data (Data Cleaning)

Dimana data di proses secara clining untuk menghilangkan data yang dapat menimbulkan data tidak konsisten dan tidak relevan. Data tersebut diperoleh dari database yang setelah dianalisis data tersebut tidak sempurna atau adanya data yang telah hilang, proses cleaning ini mecari data yang tidak valid karena salah ketik atau atribut data yang tidak sesuai. Dengan pembersihan data tersebut akan memberikan kemudahan dalam melakukan proses data mining.

2. Tahapan Integrasi data (Data Integration)

Proses integrasi didalam data mining tersebut dilakukan dengan penggabungan dari sumber beberapa jenis database yang digunakan atau beberapa file. Integrasi data ini digunakan untuk mengambil
p-ISSN : 1858-3911, e-ISSN : 2614-5405

https://journal.uniku.ac.id/index.php/ilkom

beberapa atribut yang akan diperlukan untuk dilakukan proses data mining. Bila telah dilakukan integrasi data akan memudahkan dalam melihat data yang sebenarnya, baik data yang ada ataupun data yang tidak ada.

3. Tahapan Seleksi Data (Data Selection)

Dalam proses ini data dilakukan proses seleksi, data yang dileksi hanya data atribut yang pentingnya saja, seperti data nama hanya diambil id_nama saja.

4. Tahapan Transformasi Data (Data Transformation)

Transformation merupakan proses yang mempunyai peran dalam melakukan perubahan dan integrasi skema serta struktur yang berbedabeda kedalam skema dan struktur yang terdefinisi dalam data warehouse [1].

5. Tahapan Proses Mining,

Proses Data mining merupakan proses untuk menggali (mining) pengetahuan dan informasi baru dari data yang berjumlah banyak pada data warehouse, dengan menggunakan kecerdasan buatan (Artificial Intelegence) [1], statistik dan matematika. Data mining ini merupakan teknologi yang diharapkan mampu menghubungkan komunikasi antara data-data dan pelakunya.

6. Tahapan Evaluasi Pola (Pattern Evaluation),

Dalam evaluasi pola-pola didalam data mining terdapat pola-pola model prediksi apakah sudah tercapai. Apabila data mining belum tercapai bisa menggunakan metode data mining yang lainnya, atau yang sesuai. Bisa juga menerima hasil proses data mining yang mungkin dapat bermanfaat hasilnya diluar dugaan. 
JURNAL NUANSA INFORMATIKA

Volume 15 Nomor 1, Januari 2021

7. Tahapan Presentasi Pengetahuan (Knowledge Presentation),

Proses dimana cara mengetahui metode yang digunakan dalam proses data mining. Proses data mining yaitu dapat menarik keputusan yang didapat dalam proses tersebut. Karena ada sebagian orang yang tidak mengetahui tentang data mining. Maka dalam memproses data mining harus dilakukan dengan cara menghasilkan proses yang bisa dipahami oleh banyak orang. Bisa dilakukan dengan melakukan presentasi dan visualisasi yang didapatkan dari hasil proses data mining.

\section{HASIL DAN PEMBAHASAN}

Di dalam penelitian yang dilakukan untuk mencari minat baca mahasiswa diperoleh dari judul koleksi buku yang sering banyak dipinjam pada perpustakaan Akper RS. Dustira Cimahi. Tingkat minat baca dapat dilihat dengan metode cluster yang diambil dari data judul koleksi buku yang sering banyak dipinjam pada perpustakaan Akper RS. Dustira Cimahi

Data tersebut diambil dari data perpustakaan Akper RS. Dustira Cimahi yaitu tabel koleksi buku, tabel visitorlog dan tabel anggota untuk diperoleh keterkaitan dari tiap tabel. Tidak semua dari tiap tabek diambil data atau atribut untuk dilakukan proses data mining, karena jika semua atribut diambil akan membuat proses data mining menjadi lama serta tingkat keakuratan datanya pun menjadi rendah. Dari Data peminjaman koleksi buku yang akan dilakukan proses da nada hubungannya yaitu proses id_visitorlog, date, time, id_anggota, dan code_koleksi.

\subsection{Sumber Data}

Data yang akan diproses berasal dari data perpustakaan Akper RS.
p-ISSN : 1858-3911, e-ISSN : 2614-5405

https://journal.uniku.ac.id/index.php/ilkom

Dustira Cimahi yaitu berasal dari database perpustakaan yang diambil dari tiga tabel utama, yaitu tabel data koleksi buku, tabel data peminjaman buku dan tabel data anggota.

1. Tabel Koleksi Buku (Koleksi Buku)

Data tabel koleksi buku yaitu tabel data buku yang masuk kedalam database koleksi dan dimasukan atau diinput oleh orang pustakawan pada sistem perpustakaan dan data tersebut dapat digunakan untuk proses transaksi buku yang dibaca ataupun dipinjam mahasiswa yang mengunjungi perpustakaan Akper RS. Dustira..

Tabel 1. Atribut Koleksi

\begin{tabular}{|l|l|}
\hline \multicolumn{1}{|c|}{ Atribut } & \multicolumn{1}{|c|}{ Keterangan } \\
\hline Item Code & $\begin{array}{l}\text { Item Code adalah kode } \\
\text { unik per item koleksi }\end{array}$ \\
\hline Title & $\begin{array}{l}\text { Title adalah judul buku } \\
\text { yang berhubungan } \\
\text { dengan id buku }\end{array}$ \\
\hline Author & $\begin{array}{l}\text { Author adalah penulis } \\
\text { koleksi }\end{array}$ \\
\hline Publisher & $\begin{array}{l}\text { Publisher adalah nama } \\
\text { penerbit koleksi }\end{array}$ \\
\hline $\begin{array}{l}\text { Published } \\
\text { Year }\end{array}$ & $\begin{array}{l}\text { Publisher Year adalah } \\
\text { tahun terbit koleksi }\end{array}$ \\
\hline $\begin{array}{l}\text { Publisher } \\
\text { Place }\end{array}$ & $\begin{array}{l}\text { Publisher Place adalah } \\
\text { kota terbit dari mana } \\
\text { koleksi tersebut } \\
\text { diterbitkan. }\end{array}$ \\
\hline Classification & $\begin{array}{l}\text { Classification adalah } \\
\text { nomor klasifikasi } \\
\text { koleksi }\end{array}$ \\
\hline Call Number & $\begin{array}{l}\text { Call Number adalah } \\
\text { nomor panggil koleksi }\end{array}$ \\
\hline
\end{tabular}

\section{Tabel Anggota}

Dimana data tersebut diambil dari mahasiswa yang terdaftar diperpustakaan dan sudah menjadi member perpustakaan tersebut, sehingga bisa meminjam buku diperpustakaan. 
JURNAL NUANSA INFORMATIKA

Volume 15 Nomor 1, Januari 2021

Tabel 2. Atribut Anggota

\begin{tabular}{|c|c|}
\hline Atribut & \\
\hline Member ID & $I d$ adalah primary key \\
\hline $\begin{array}{l}\text { Member } \\
\text { Name }\end{array}$ & $\begin{array}{l}\text { First_name adalah } \\
\text { nama mahasiswa }\end{array}$ \\
\hline Birth_date & $\begin{array}{l}\text { Birth_date } \\
\text { tanggal lahir }\end{array}$ \\
\hline $\begin{array}{l}\text { Member } \\
\text { Since }\end{array}$ & $\begin{array}{l}\text { Member Since adalah } \\
\text { penanda waktu selama } \\
\text { menjadi anggota }\end{array}$ \\
\hline $\begin{array}{l}\text { Register } \\
\text { Date }\end{array}$ & $\begin{array}{l}\text { Register Date adalah } \\
\text { Tanggal Mendaftar } \\
\text { menjadi Anggota }\end{array}$ \\
\hline $\begin{array}{l}\text { Expiry } \\
\text { Date }\end{array}$ & $\begin{array}{l}\text { Expiry Date adalah } \\
\text { Tanggal Masa Berlaku } \\
\text { menjadi Anggota }\end{array}$ \\
\hline Institl & $\begin{array}{l}\text { Institution adalah nama } \\
\text { institusi anggota }\end{array}$ \\
\hline $\begin{array}{l}\text { Member } \\
\text { Type }\end{array}$ & $\begin{array}{l}\text { Member Type adalah } \\
\text { Tipe Anggota }\end{array}$ \\
\hline Gender & $\begin{array}{l}\text { Gender adalah jenis } \\
\text { kelamin anggota }\end{array}$ \\
\hline Address & Address adalah alamat \\
\hline $\begin{array}{l}\text { Phone } \\
\text { Number }\end{array}$ & $\begin{array}{l}\text { Phone Number adalah } \\
\text { nomor telepon anggota }\end{array}$ \\
\hline$e$-mail & $\begin{array}{l}\text { e-mail adalah alamat } \\
\text { surat elektronik anggota }\end{array}$ \\
\hline
\end{tabular}

3. Tabel Visitorlog (Peminjaman)

Data ini diambil dari data sirkulasi peminjaman buku, dimana mahasiswa melakukan proses peminjaman buku dan dilakukan input data oleh pustakawan yang ada di perpustakaan Akper RS. Dustira.

Tabel 3. Artibut Visitorlog

\begin{tabular}{|l|l|}
\hline \multicolumn{1}{|c|}{ Atribut } & \multicolumn{1}{c|}{ Keterangan } \\
\hline Member ID & $\begin{array}{l}\text { Member ID adalah } \\
\text { kode primary key }\end{array}$ \\
\hline Visitor Name & Nama pengunjung \\
\hline $\begin{array}{l}\text { Membership } \\
\text { Type }\end{array}$ & Tipe keanggotaan \\
\hline Institution & Institusi Anggota \\
\hline Visit Date & Tanggal Kunjungan \\
\hline
\end{tabular}

p-ISSN : 1858-3911, e-ISSN : 2614-5405

https://journal.uniku.ac.id/index.php/ilkom

Dalam proses data mining ini digunakan data yang berasal, yaitu dari database perpustakaan. Data ini didasarkan oleh kebutuhan yang dimana akan diproses dan dihubungkan dengan tabel data koleksi, tabel data anggota dan tabel visitorlog data peminjaman, berdasarkan kesimpulan atau asumsi bahwa tingkat minat baca mahasiswa dalam meminjam koleksi buku diperpustakaan dapat diperoleh dari jumlah judul koleksi buku yang selalu banyak dipinjam oleh mahasiswa pada perpustakaan tersebut.

\subsection{Data Mining}

Dalam proses data mining ini dilakukan dengan cara membangun suatu data warehouse yang dimanfaatkan untuk menyimpan data yang diperoleh dari database perpustakaan yang diambil dari tabel koleksi buku, tabel visitorlog atau peminjaman buku dan tabel anggota. Data Warehouse adalah kumpulan beragam fakta dan angka yang diproses yang disimpan terpisah dari database operasional serta yang mendukung pembuatan laporan dan analisis data pada suatu unit, bagian operasi pada suatu perusahaan [4]. Maksud tujuan utama untuk membangun data warehouse yaitu agar database tersebut tidak terjadi masalah, kemudian dalam data warehouse ini dapat memudahkan dalam proses menggabungkan data yang diambil dari tiga tabel tersebut. Proses ETL (Ekstrak, Transform, and Load) dalam membuat data warehouse merupakan tahapan proses yang sangat penting sebab data warehouse menentukan pembuatan menuju data warehouse dalam tahapan yang berikutnya.

Pada database perpustakaan yang akan dipakai untuk proses dan juga sebagai sumber data yang akan di import kedalam SQL SERVER2008R2 yang 
JURNAL NUANSA INFORMATIKA

Volume 15 Nomor 1, Januari 2021
p-ISSN : 1858-3911, e-ISSN : 2614-5405

https://journal.uniku.ac.id/index.php/ilkom menjadi tempat proses untuk penyimpanan database perpustakaan. Proses ETL (Ekstrak, Transform, and Load). SQL Server Adalah bahasa standar yang digunakan untuk mengakses server database [5]. Pada proses pengambilan data, dimana data yang akan digunakan adalah data koleksi buku, data visitorlog atau peminjaman buku dan data anggota perpustakaan, selanjutnya akan dilakukan proses untuk dibuat sebuah data warehouse, kemudian data tersebut dijadikan satu atau digabungkan. Sebelum merancang suatu data warehouse dibangun terlebih dahulu analisi design. Analisis Design adalah merancang suatu kebutuhan suatu sistem sebelum sistem tersebut dibangun [6]. Dalam proses ini data tersebut akan dijadikan sebuah data warehouse, kemudian data tersebut dapat diproses selanjutnya kedalam proses data mining yang dinamakan dengan proses yaitu SSAS.

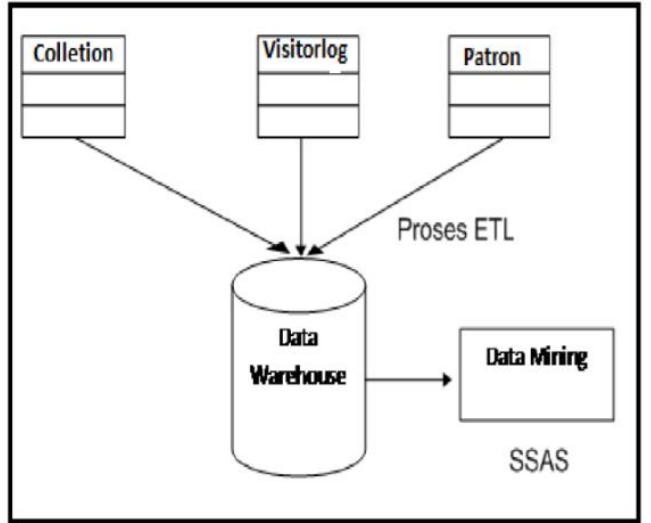

Gambar 1. Konsep proses ETL (ekstrak, transform, and loading).

Dalam membuat proses data warehouse ini, diambil berdasarkan dari tiga tabel utama yaitu tabel koleksi buku, tabel visitorlog peminjaman buku dan tabel anggota perpustakaan yang kemudian akan disatukan menjadi satu tabel dan dijadikan sebagai sebuah data warehouse, data yang kemudian akan dijadikan sebagai proses data warehouse adalah data visitorlog peminjaman buku dimana atributnya telah dipilih untuk dilakukan analisis agar mempermudah dalam proses pengambilan suatu keputusan. Dalam melakukan proses pembuatan data tersebut dari database kedalam data warehouse dilakukan dengan melalui yang dinamakan proses ETL, Extraction merupakan proses untuk mengidentifikasi seluruh sumber data yang relevan dan mengambil data dari sumber data tersebut. Penentuan pendekatan yang digunakan pada proses ekstrasi sangat terkait dengan analisis bisnis proses, pendefinisian area subjek, serta desain logik/fisik data warehouse. Transformation merupakan proses yang mempunyai peran dalam melakukan perubahan dan integrasi skema serta struktur yang berbeda-beda kedalam skema dan struktur yang terdefinisi dalam data warehouse. Loading merupakan proses pemindahan data secara fisik dan sistem operasional kedalam data warehouse. proses tersebut menggunakan sebuah basis data. Basis Data adalah terdiri dari dua kata, basis dan data. Basis dapat diartikan kurang lebih sebagai markas, gudang atau tempat berkumpul. Sedangkan data adalah repesentasi fakta dunia nyata yang mewakili suatu objek seperti manusia (pegawai, siswa, pembeli dan lain - lain), barang dan sebagainya yang direkam dalam bentuk angka, huruf, simbol, teks, gambar, bunyi atau kombinasi lainnya [7].

\begin{tabular}{|c|c|}
\hline Collection & Pengabungan Data \\
\hline id_collection & \\
\hline title & id_visitorlog \\
\hline publisher & date \\
\hline \multirow{3}{*}{$\begin{array}{l}\text { publisher_city } \\
\text { publisher_year }\end{array}$} & time_in \\
\hline & id_patron \\
\hline & title \\
\hline Visitorlog & publisher \\
\hline \multirow{2}{*}{$\begin{array}{l}\text { id_patron } \\
\text { name }\end{array}$} & publisher_city \\
\hline & publisher_year \\
\hline \multirow{2}{*}{ sex } & name \\
\hline & $\operatorname{sex}$ \\
\hline \multirow{2}{*}{$\begin{array}{l}\text { birth_place } \\
\text { program studi }\end{array}$} & address \\
\hline & birth_place \\
\hline & program studi \\
\hline
\end{tabular}


JURNAL NUANSA INFORMATIKA

Volume 15 Nomor 1, Januari 2021

Gambar 2. Pengabungan data (data warehouse)

Semua data tersebut terdapat pada tabel anggota dan tabel koleksi buku diimport atau dimasukan ke dalam data warehouse, tetapi jika terdapat ada data yang sama dari kedua tabel tersebut seperti, id_anggota, id_koleksi dan data yang lain, maka data yang akan di load hanya salah satu dari data tabel tersebut dengan perkiraan bahwa data tersebut memiliki nilai data yang sama. Hal tersebut dilakukan agar supaya tidak ada data yang memiliki kesamaan atau redudancy data yang dapat membuat data rangkap.

\subsection{Data Transformation (Transformasi Data)}

Dalam memproses data menjadi suatu data mining maka sumber data tersebut yang akan digunakan dalam bentuk format database Mysql akan dilakukan konversi atau dirubah kedalam bentuk format Microsoft Office Excel. Dengan alasan bahwa menggunakan Microsoft Office Excel dapat mempermudah proses imfort atau proses memasukan data kedalam sebuah data Sql Server Management Studio sehingga prpses database tersebut dapat diolah sesuai dengan apa yang diinginkan atau dibutuhkan. Pada proses ini transformasi dilakukan juga sekaligus dengan pembersihan data dan juga seleksi data. Dalam proses ini dapat dihasilkan data dengan bentuk format Microsoft Office Excel yang dapat diliahat pada gambar 3 dibawah ini, yaitu data transformasi.
p-ISSN : 1858-3911, e-ISSN : 2614-5405

https://journal.uniku.ac.id/index.php/ilkom

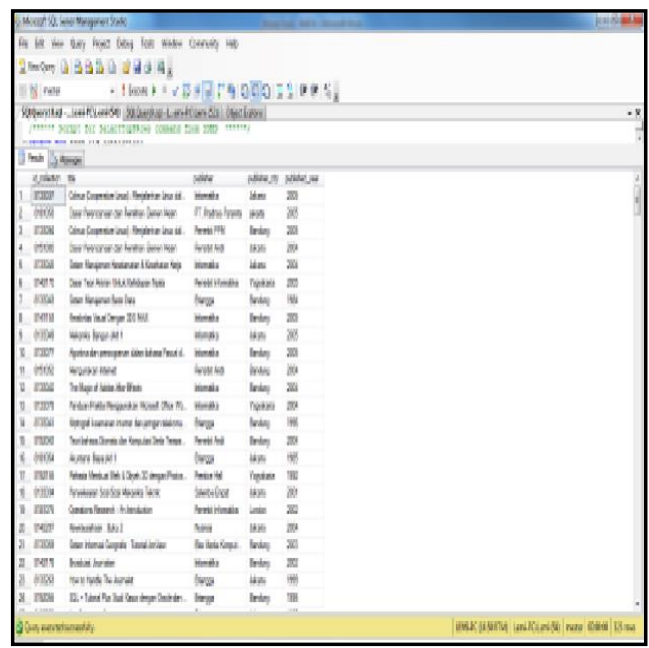

Gambar 3. Data Transformasi

\subsection{Data Warehouse}

Data Warehouse adalah kumpulan beragam fakta dan angka yang diproses yang disimpan terpisah dari database operasional serta yang mendukung pembuatan laporan dan analisis data pada suatu unit, bagian operasi pada suatu perusahaan [4]. Didalam proses data warehouse ini akan dibuat suatu data warehouse yang kemudian akan digunakan untuk menjadi tempat suatu data dari database perpustakaan Akper RS. Dustira Cimahi yang terdapat dari tabel koleksi buku, table anggota dan tabel peminjaman. Dari tabel-tabel tersebut akan dibangun tabel visitorlog yang baru didalam sebuah data warehouse.

Untuk proses pembuatan sebuah data warehouse tersebut Tambahkan OLE DB Destination untuk disatukan semua data menjadi data warehouse yang dapat dilihat pada gambar 4. data warehouse dibawah ini. 
JURNAL NUANSA INFORMATIKA

Volume 15 Nomor 1, Januari 2021

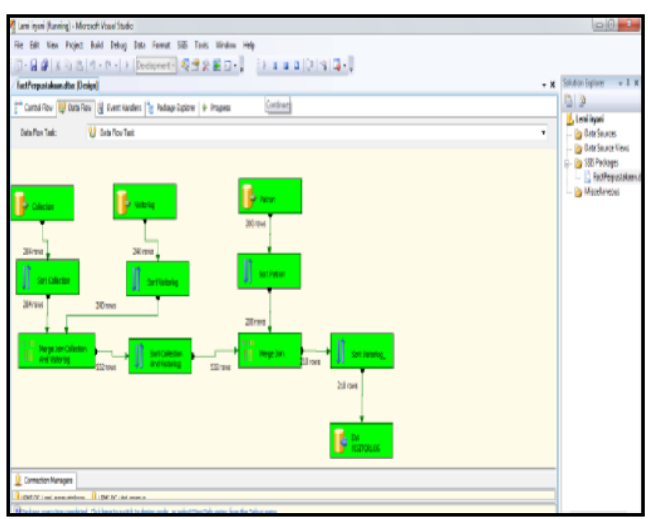

Gambar 4. Data Warehouse

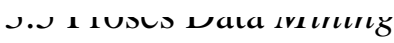

Data mining merupakan proses untuk menggali (mining) pengetahuan dan informasi baru dari data yang berjumlah banyak pada data warehouse, dengan menggunakan kecerdasan buatan (Artificial Intelegence) [1]. Dalam melakukan proses data mining dilakukan dengan cara menampilkan dari semua data yang ada dan akan diproses dengan menggunakan metode clustering untuk didapatkan hasil tingkat minat baca dari mahasiswa dan juga dalam proses peminjaman buku diperpustakaan. Proses ini dilakukan setelah dapat menentukan sebuah data warehouse yang telah dibuat sesuai berdasarkan dengan kebutuhan. Dalam proses data mining ini menggunakan system SSAS (Sql Server Analitycal Services). Untuk membangun sebuah data mining dan dapat menampilkan sebuah data tingkat minat baca mahasiswa yang diambil berdasarkan dari data judul koleksi buku diperpustakaan Akper RS. Dustira Cimahi dengan menggunakan metode clustering.
p-ISSN : 1858-3911, e-ISSN : 2614-5405

https://journal.uniku.ac.id/index.php/ilkom

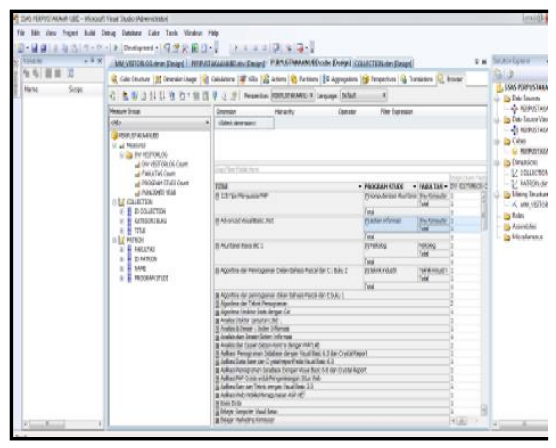

Gambar 5. Proses Data Mining

\subsection{Clustering}

Dalam Proses clustering dikumpulkan data objek yang sama kemudian akan dikelompokan menurut kesamaanya [2]. Clustering tersebut diproses setelah tahapan proses dari hasil data mining untuk ditampilkan data yang dibutuhkan dan yang akan digunakan selanjutnya dalam proses pengolahan data tersebut. Data yang akan dilakukan proses clustering yaitu data jumlah judul koleksi buku yang sangat banyak diminati oleh mahasiswa maka dapat kita lihat pada gambar 6. Clustering dibawah ini.

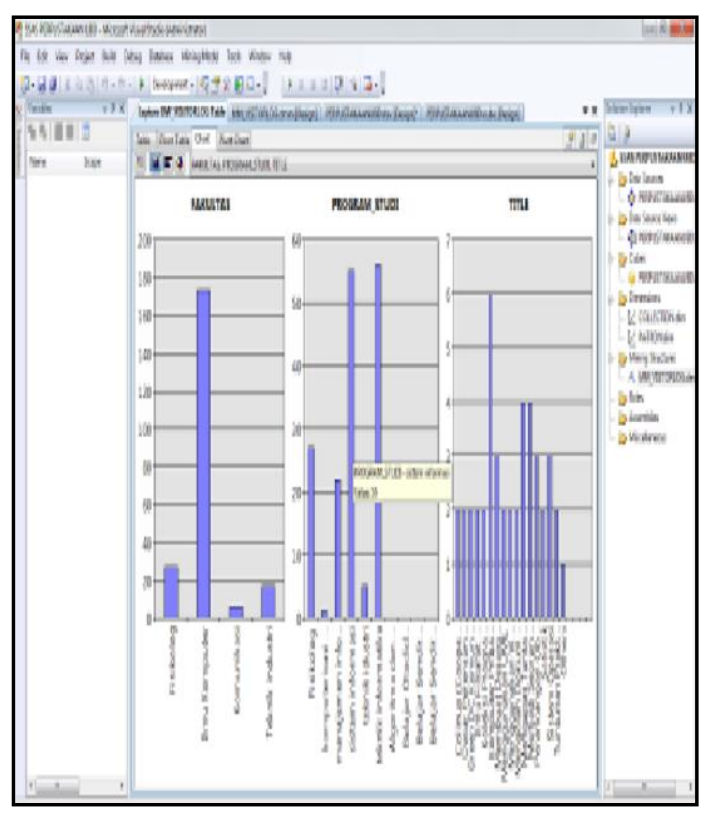

Gambar 6. Clustering 
JURNAL NUANSA INFORMATIKA

Volume 15 Nomor 1, Januari 2021

\section{KESIMPULAN}

Berikut ini adalah kesimpulan yang dapat diambil dalam penelitian yang telah dilakukan, yaitu:

1. Menerapkan data mining tersebut untuk sistem informasi dalam menetukan tingkat minat baca mahasiswa di unit Perpustakaan Akper RS. Dustira Cimahi dengan menggunakan metode clustering .

2. Dalam proses penelitian ini didapat Informasi yang akan ditampilkan yaitu berupa data koleksi buku yang diminati oleh mahasiswa yaitu buku Pengantar Kebutuhan Dasar Manusia.

Dari kesimpulan tersebut terdapat hasil adanya perbedaan antara mahasiswa yang sering meminjam koleksi buku, maka dapat disimpulkan bahwa mahasiswa tingkat akhir lebih berminat untuk mengunjungi perpustakaan dan sering meminjam buku di perpustakaan, berbanding terbalik dengan mahasiswa yang masih semester awal atau mahasiswa baru.

\section{SARAN}

Hasil penelitian ini dapat menjadi acuan bagi pengambil kebijakan (stakeholder) khususnya untuk dijadikan bahan evaluasi untuk lebih meningkatkan minat baca.

Diharapkan metode clustering menggunakan data mining ini dapat digunakan sebagai salah satu metode untuk mengukur minat baca mahasiswa di Perpustakaan.

\section{DAFTAR PUSTAKA}

[1] Golfarelli, M., Hill, M.G., dan Rizzi, S.2009. Data Warehouse Design, Modern Principles and Methodologies. New York: Mc Graw Hill.
p-ISSN : 1858-3911, e-ISSN : 2614-5405

https://journal.uniku.ac.id/index.php/ilkom

[2] Agustin, W. (2018). Penerapan Metode Clustering K-Means dan Metode Six Sigma untuk Mengetahui Tingkat Minat Baca Mahasiswa. SATIN-Sains dan Teknologi Informasi, 3(1), 22-31.

[3] Saputra, N. E., Tania, K. D., \& Heroza, R. I. (2016). Penerapan Knowledge Management System (KMS) Menggunakan Teknik Knowledge Data Discovery (KDD) Pada Pt Pln (Persero) Ws2jb Rayon Kayu Agung. Sriwijaya Journal of Information Systems, 8(2), 131900.

[4] Inmon, William H. 2005. "Building The Data Warehouse (4th ed.)". Indianapolis : Wiley Publishing, Inc..

[5] Rainardi, Vincent.2008. "Building a Data Warehouse with Examples in SQL Server". New York : Springer.

[6] Jogiyanto HM, Akt MBA. 2006. Analisis dan Desain Sistem Informasi. Yogyakarta : Andi

[7] Nugroho, Adi, 2004, "Konsep Pengembangan Sistem Basis Data", Informatika, Bandung. 